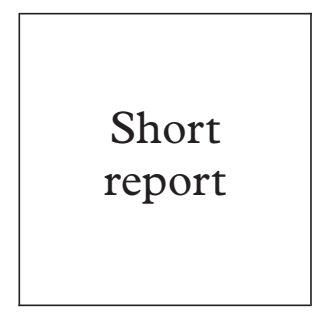

\title{
No association of anti-Chlamydia trachomatis antibodies and severity of cervical neoplasia
}

\author{
N Reesink-Peters, J M Ossewaarde, A G J Van Der Zee, W G V Quint, M P M Burger, \\ A H Adriaanse
}

Objective: To explore whether the presence of Chlamydia trachomatis antibodies is associated with the severity of neoplastic lesions in women with cervical dyskaryosis.

Methods: In a cross sectional study in two groups of women referred for an abnormal Papanicolaou smear (group A: 296, group B: 331 women) blood samples were analysed for antichlamydial antibodies by enzyme immunoassay. Cervical neoplasia was graded histologically.

Results: In group A no association was found between increasing grade of CIN and the presence of antichlamydial antibodies. The proportion (93\%) of women with antichlamydial antibodies was higher in 14 women with (micro)invasive carcinoma than in women with CIN (35\%). As the high prevalence of antichlamydial antibodies in women with cervical carcinoma is not consistent with prevalences reported in recent literature, we analysed a second group of women in which indeed the high prevalence was not confirmed

Conclusion: Our results suggest that the presence of circulating antichlamydial antibodies is not associated with the severity of neoplastic lesions and it seems unlikely that $C$ trachomatis has a role in the progression of cervical neoplasia.

(Sex Transm Inf 2001;77:101-102)

Keywords: cervical neoplasia; Chlamydia trachomatis

\section{Introduction}

Human papillomavirus (HPV) has an important role in the development of cervical intraepithelial neoplasia (CIN) and cervical carcinoma. However, compared with the high rates of HPV infections in women without cervical neoplasia, the occurrence of CIN and cervical cancer is rare. ${ }^{1}$ The search for risk factors for cervical neoplasia, other than HPV, is therefore still ongoing. A candidate risk factor is Chlamydia trachomatis. Case-control studies have reported that serum antibodies against $C$ trachomatis are relatively more frequent in women with CIN or cervical carcinoma compared with controls. ${ }^{2-7}$

In the present study we explored the hypothesis that the presence of $C$ trachomatis antibodies is associated with the severity of neoplastic lesions using a cross sectional study design. An (unexpected) high prevalence of antichlamydial antibodies in women with (micro)invasive carcinoma ((M)IC) was found. This high prevalence of antichlamydial antibodies in women with (M)IC and a higher prevalence in women with (M)IC than in women with CIN III was not reported previously. ${ }^{2-7}$ Therefore, a second study population was selected in an attempt to confirm our results.

Delft Diagnostic Laboratory, Delft W G V Quint

Correspondence to: A $\mathrm{H}$ Adriaanse, $\mathrm{MD}, \mathrm{PhD}$, Division of Obstetrics and Gynaecology, Academic Medical Centre, PO Box 22660, 1100 DD

Amsterdam, Netherlands

a.h.adriaanse@amc.uva.nl

Accepted for publication 14 November 2000

\section{PATIENTS}

Methods

Two groups of women referred for an abnormal Papanicolaou smear to the gynaecological outpatient clinic of the University Hospital Groningen, Netherlands, were recruited for this study. Group A comprised 296 women referred between September 1988 and September $1993^{\circ}$ and group B comprised 331 women referred between November 1995 and June 1999. For both groups separately, the study was approved by the ethics review board of the hospital.

QUESTIONNAIRE

Using a structured questionnaire, women were asked about their smoking habits and their lifetime number of sexual partners.

DETECTION OF SERUM ANTIBODIES AGAINST $C$ TRACHOMATIS

Blood samples were taken at the enrolment visit of all women. Periodate treated enzyme immunoassays (EIA) were carried out as described previously. ${ }^{9}{ }^{10}$ Treatment with sodium periodate results in enhanced specificity of the assay compared with the native EIA. ${ }^{9}$ For both groups of patients, the same reference serum was used ensuring comparability of the results.

\section{MORPHOLOGICAL EXAMINATION}

Colposcopically directed biopsies were taken and graded according to the criteria of the World Health Organization. ${ }^{11}$ If CIN was diagnosed, except for CIN I in group B, the whole transformation zone was subsequently excised by loop electrosection (LETZ) or cold knife conisation. Cervical neoplasia was classified according to the most severe histological lesion found.

\section{Results}

In group A 114 (39\%) of 296 women tested positive for serum antibodies against $C$ trachomatis. The prevalence of antichlamydial antibodies did not increase significantly with 
Table 1 Antibodies against $C$ trachomatis and the grade of neoplasia

\begin{tabular}{llllll}
\hline & \multicolumn{5}{l}{ No (\%) of positives for antibodies against $C$ trachomatis, and the $95 \%$ CI } \\
\cline { 2 - 6 } & \multicolumn{1}{l}{ Grade of neoplasia } \\
\cline { 2 - 6 } & None & CIN I & CIN II & CIN III & $(M) I C$ \\
\hline Group A & $16 / 40(40)$ & $8 / 34(24)$ & $14 / 43(33)$ & $63 / 165(38)$ & $13 / 14(93)^{\star}$ \\
& $25-57$ & $10-41$ & $19-49$ & $31-46$ & $66-100$ \\
Group B & $8 / 19(42)$ & $26 / 50(52)$ & $41 / 82(50)$ & $74 / 153(48)$ & $15 / 27(55)$ \\
& $20-67$ & $37-66$ & $39-61$ & $40-56$ & $35-75$ \\
\hline
\end{tabular}

${ }^{\star} \chi^{2}$ test, $\mathrm{p}<0.001$.

$\chi^{2}$ test for trend was not significant for both groups.

Table 2 Patient characteristics for group $A$ and $B$

\begin{tabular}{lllll}
\hline & \multicolumn{2}{l}{ Group A } & \multicolumn{2}{l}{ Group B } \\
\hline $\begin{array}{lllll}\text { Age (median, interquartile range) } \\
\text { Life time number of sexual partners (median, }\end{array}$ & 35 & $29-39$ & 35 & $31-42$ \\
$\quad$ interquartile range) & 4 & $2-10$ & 4 & $2-8$ \\
Sexarche $\leqslant 17$ years (\%, 95\% CI) & 52 & $46-57$ & 49 & $43-54$ \\
Smoker (\%, 95\% CI) & 65 & $59-70$ & 69 & $64-75$ \\
No dysplasia (\%, 95\% CI) & 14 & $9.6-17$ & 5.7 & $3.5-8.8$ \\
CIN I (\%, 95\% CI) & 12 & $7.9-15$ & 15 & $11-19$ \\
CIN II (\%, 95\% CI) & 15 & $11-19$ & 25 & $20-29$ \\
CIN III (\%,95\% CI) & 56 & $50-61$ & 46 & $41-52$ \\
(M)IC (\%, $\% 5 \%$ CI) & 4.7 & $2.6-7.8$ & 8.2 & $5.5-11.7$ \\
\hline
\end{tabular}

increasing severity of CIN. However, the prevalence of $C$ trachomatis antibodies was significantly higher in the group of women with (M)IC than in women with CIN (table 1).

Patient characteristics in group B met the characteristics of group A apart from the proportion of women diagnosed with no dysplasia or CIN II, for which the $95 \%$ confidence intervals did not overlap (table 2). Serum antibodies against $C$ trachomatis were found in $164(50 \%)$ of 331 women in group B. No increasing trend was observed for the proportion of women positive for antichlamydial antibodies with increasing severity of CIN (table 1). The prevalence of $C$ trachomatis antibodies in women with (M)IC was not significantly higher than in women with CIN.

\section{Discussion}

Differences between groups A and B might occur because of systematic differences between the two groups or because of chance. Effort was made to reduce systematic differences: periodate treated EIA was performed for both groups separately, but the same reference serum was used. Criteria for eligibility for group A and group B corresponded. We therefore have no other explanation than that the difference in the proportion of women with no dysplasia and CIN II is due to chance. The reported differences appeared to have no implication for our results.

Overall prevalences of antichlamydial antibodies were comparable for groups $\mathrm{A}$ and $\mathrm{B}$. However, $93 \%$ of the women with (M)IC in group A had antichlamydial antibodies compared with $55 \%$ in group B. Prevalences reported by others are comparable with the prevalence found in group B. ${ }^{2-7}$ The number of women with (M)IC in group A is low. The $95 \%$ $\mathrm{CI}$ of the prevalence is very wide in this group and overlaps the $95 \%$ CI of the proportion observed in the same category of group B (table 2). Chance has a great effect on small study populations. ${ }^{12}$ Considering what is discussed above we conclude that the high prevalence in the (M)IC group of A is due to chance.

The role of $C$ trachomatis in the aetiology of cervical neoplasia is hard to interpret. Many studies reported antichlamydial antibodies to be more frequent in women with cervical neoplasia than in controls. ${ }^{2-7}$ This might indicate that $C$ trachomatis has a causal role in cervical carcinogenesis. Our results suggest that $C$ trachomatis does not favour the progression from CIN to invasive disease. However, it should be kept in mind that these serological data can not exclude the possible involvement of local factors induced by (chronic) $C$ trachomatis infections.

Contributors: NR was the main author of the article and performed the statistical analysis; JMO performed the EIAs and was the author of the $C$ trachomatis methods section; AGJVdZ was the author of the $C$ trachomatis methods section; AGJVdZ
collected the patient samples of group B whereas MPMB collected the patient samples of group B whereas MPMB
collected the samples for group A and supervised the research collected the samples for group A and supervised the research
programme; WGVQ advised on the methodology of the study programme; WGVQ advised on the methodology of
and AHA was coauthor of the article and supervisor.

1 Munoz N, Bosch FX. HPV and cervical neoplasia: review of case-control and cohort studies. [Review] [28refs]. IARC Sci Publ 1992:251-61.

2 Stone KM, Zaidi A, Rosero-Bixby L, et al. Sexual behavior, sexually transmitted diseases, and risk of cervical cancer. Epidemiology 1995;6:409-14.

3 Schachter J, Hill EC, King EB, et al. Chlamydia trachomatis and cervical neoplasia. $\mathcal{F} A M A$ 1982;248:2134-8.

4 Hakama $M$, Lehtinen $M$, Knekt $P$, et al. Serum antibodies and subsequent cervical neoplasms: a prospective study with 12 years of follow-up. Am F Epidemiol 1993;137:16670

5 Dillner J, Lenner P, Lethtinen $\mathrm{M}$, et al. A population-based seroepidemiologic study of cervical cancer. Cancer Res 1995;54:134-41.

6 Moreno V, Munoz N, Bosch FX, et al. Risk factors for progression of cervical intraepithelial neoplasm grade III to invasive cervical cancer. Cancer Epidemiol Biomarkers Prev 1995;4:459-67.

7 Koskela P, Antilla T, Bjorge T, et al. Chlamydia trachomatis infection as a risk factor for invasive cervical cancer. Int $\mathcal{F}$ Cancer 2000;85:35-9.

8 Burger MP, Hollema H, Pieters WJ, et al. Epidemiological evidence of cervical intraepithelial neoplasia without the presence of human papillomavirus. Br f Cancer 1996;73: presence.

9 Ossewaarde JM, de Vries A, van den Hoek JA, et al. Enzyme immunoassay with enhanced specificity for detection of
antibodies to Chlamydia trachomatis. F Clin Microbiol 1994;32:1419-26.

10 Ossewaarde JM, Manten JW, Hooft HJ, et al. An enzyme immunoassay to detect specific antibodies to protein and lipopolysccharide antigens of Chlamydia trachomatis. $\mathcal{F}$ Immunol Methods 1989;123:293-8.

11 Poulsen HE, Taylor CW, Sobin LH. Histological typing of female genital tract tumours. Geneva: World Health Organization, 1975.

12 Beurskens AJ, de Vet HC, Kant I. Roaming through the methodology. VIII. Pilot studies: sense and nonsense. [Dutch, summary in English]. Ned Tijdschr Geneeskd 1998; 142:2142-5. 